\title{
Синхронность сейсмогравитационных пульсаций
}

\author{
Ю. В. Антонов ${ }^{\bowtie}$, И. Ю. Антонова \\ Воронежский государственный университет \\ Университетская пл., 1, 394018, Воронеж, Российская Федерация
}

\begin{abstract}
Аннотация
Введение: Пульсации силы тяжести были впервые обнаружены при обработке стационарных наблюдений на Геодинамическом полигоне РАН в г. Бишкеке (2014 г.). Как оказалось, такие же пульсации характерны для сейсмических колебаний, которые синхронно совпадали с гравиметрическими пульсациями.

Методика: Сейсмические и гравиметрические наблюдения осложнены влиянием Луны и Солнца. Основной задачей при обработке является исключение этого влияния. Исключение лунно-солнечного влияния производится путем теоретических расчетов лунно-солнечных вариаций силы тяжести и их временного градиента. Кроме того, сейсмо-гравиметрические измерения подвержены влиянию атмосферного давления и температуры воздуха. Метеорологические помехи устраняются использованием метода осреднения.

Результаты и обсуждение: Анализ сейсмогравитационных пульсаций на различных континентах показал, что пульсации полностью синхронны между собой. Такая синхронность характерна в основном для внутриконтинентальных станций. Таким образом, на основании изучения сейсмогравитационных пульсаций можно утверждать о наличии двух типов источников. Первый тип пульсаций связан с ударами метеорных потоков по земной атмосфере, для него присущ планетарный характер. В прибрежных зонах и в океане дополнительно возникают пульсации за счет атмосферных процессов (тайфуны, циклоны и т.д.)

Bblвodbl: Полученные результаты в дальнейшем могут быть использованы при изучении внутреннего строения Земли, для определения мощности метеорных потоков и повышения точности гравиметрических измерения.

Ключевые слова: лунно-солнечные вариации силы тяжести; неприливные вариации силы тяжести; корональные выбросы масс; метеорные потоки; пульсации; сейсмический шум.

Для цитирования: Антонов Ю. В., Антонова И. Ю. Синхронность сейсмогравитационных пульсаций // Вестиик Воронежского государственного университета. Серия: Геология. 2020. №2. С. 7682. DOI: https://oi.org/10.17308/geology.2020.2/2861
\end{abstract}

\section{Введение}

Прибором для измерения гравитационного поля и сейсмических колебаний служит маятник Голицына. Изменение гравитационного поля во времени влечет за собой возникновение сейсмических колебаний с тем же периодом. По существу, сейсмическое поле является производной по времени от гравитационного [1].
Следовательно, если сила тяжести не меняется, то сейсмические колебания отсутствуют. И наоборот, если не имеется землетрясений, взрывов, выбросов корональных масс и т.д., то не возникает дополнительных изменений силы тяжести. В целом же динамическая система сейсмических и гравитационных колебаний существует взаимоувязанно и не всегда можно выделить первопричину этих колебаний.

Контент доступен под лицензией Creative Commons Attribution 4.0 License.

\footnotetext{
๑ Антонов Юрий Васильевич, e-mail: yuriyantonov@yandex.ru
} 


\section{Методика обработки}

Для примера рассмотрим так называемые сейсмогравитационные пульсации. Ранее [2-4] уже частично рассматривались результаты выделения и интерпретации сейсмогравитационных пульсаций. Начнем рассмотрение с сейсмических пульсаций. На рис. 1 приве- дены пульсации на различных континентах земного шара в четырех пунктах: BFO (Шварцвальд, Германия), Арти (Екатеринбург, Россия), АКК (г. Бишкек, Киргизия), и FFC (Канада). Забегая несколько вперед, отметим, что касается сейсмометрии в отличие от гравиметрии, можно привести очень больший список обсерваторий.

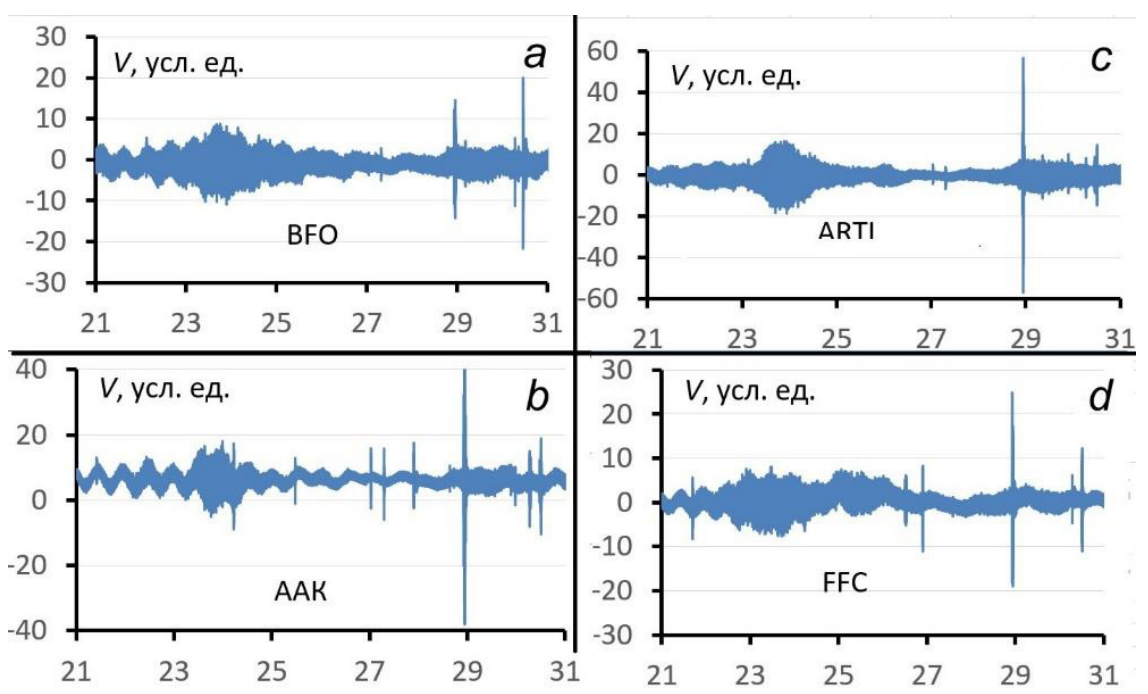

Рис. 1. Пульсации сейсмического полей на континентах 21-31 марта 2019 г.: $a$ - BFO (Шварцвальд, Германия); $b$ - AАK (Бишкек, Киргизия); $c$ - ARTI (Екатеринбург, Россия; $d$ - FFC (Канада).

[Fig. 1. Pulsations of seismic fields on the continents 21-31 March 2019: $a-\mathrm{BFO}$ (black forest, Germany); $b-$ AAK (Bishkek, Kyrgyzstan); $c-$ ARTI (Yekaterinburg, Russia); $d-$ FFC (Canada).]

Несмотря на то, что данные получены различными типами приборов и на различных континентах, пульсации четко совпадают между собой. Такие совпадения пульсаций сейсмологи чаще всего не замечают или, скорее всего, не хотят их замечать. Считается, что сейсмические пульсации возникают за счет ударов морских волн о побережье $[2,5]$. Где расположены пункты, представленные на рис. 1, относительно океанов? Станция FFC расположена ближе всего к Тихому океану, BFO - к Атлантическому, Арти - к Северному Ледовитому, а ААК - к Индийскому. Трудно представить, что все океаны синхронно колебались, вызывая пульсации. Поэтому, синхронность пульсаций автор склонен объяснять космическими причинами $[3,4]$.

Метеорные потоки ударяют по земной атмосфере, которая начинает колебаться. Плотность потока меняется во времени, поэтому амплитуды колебаний сейсмического поля тоже меняется. Но, главное, что пульсации можно объяснить ударами метеорных потоков это периодичностью появления пульсаций. Например, пульсации метеорного потока Квадрантиды ежегодно проявляются в последних числах декабря и начале января или Аквариды во второй половине апреля. Рассматриваемые пульсации на рис. 1 связаны с потоком Виргиниды. Пульсация 30 марта может быть связана с Дельта Павонидами. Но данный поток очень слабый. Возможно, наложение этих потоков совместно, так как Виргиниды действуют весь март и первую половину апреля. Кстати, автор согласится с другим объяснением причины появления пульсаций, если оно будет убедительным. Трудно представить, что влияние прибрежных ударов волн будут иметь такие амплитуды, учитывая коэффициент затухания земной коры, упругие параметры которой достаточно хорошо известны и изучены.

После констатации факта синхронности сейсмических пульсаций уместно остановиться на способах выявления данных пульсаций. Исходные данные представлены наблюденными значениями размерностью в 4 или 8 единиц. Изменение поля во времени можно представить в виде

$$
\mathrm{V}_{\text {изи }}(\mathrm{t})=\mathrm{V}_{\text {лсв }}(\mathrm{t})+\mathrm{V}_{\text {нп }}(\mathrm{t})+\mathrm{C},
$$

где $\mathrm{V}_{\text {изи }}(\mathrm{t})$ - измеренные значения сейсмических данных; $\mathrm{V}_{\text {дсв}}(\mathrm{t})$ - значения влияния градиента лунносолнечных вариаций силы тяжести; $\mathrm{C}$ - постоянная.

Остановимся более подробно на зависимости сейсмических колебаний от лунно-солнечных вариаций, а точнее от их градиента. Обратимся к рис. 2. На рисунках 2, $a, c$ представлены исходные сейсмические данные и лунно-солнечные вариации силы тяжести. Вариации силы тяжести получены с помощью программы [6]. Размерность вариаций дана в миллигалах, которые увеличены на четыре порядка. Как видим, совпадения форм сейсмических колебаний и вариаций силы тяжести не наблюдается (рис. 2, $a, c$ ). А вот градиент вариаций (рис. $2, b$ ) по морфологии полностью совпадает с сейсмическими данными. Поскольку по амплитуде сейсмические колебания, вызванные Луной - Солнцем почти на порядок больше, чем амплитуды неприливных вариаций, то влияние последних не так сильно сказывается на морфологии исходных данных. Поэтому практическим путем легко подобрать для любого сейсмографа переходной коэффициент для пере- 
вода значений вариаций силы тяжести с переменным коэффициентом K

$$
\begin{gathered}
\Delta \mathrm{V}(\mathrm{t})=\mathrm{V}_{\text {изм }}(\mathrm{t})-\mathrm{K}^{*}\left(\partial \mathrm{g}_{\text {лсв }}(\mathrm{t}) / \partial t\right) \sim \text { Иизм }(\mathrm{t})-\mathrm{K}^{*} \\
*\left(\mathrm{~g}_{\text {лсв }}(\mathrm{t}+1)-\mathrm{g}_{\text {лсв }}(\mathrm{t})\right)
\end{gathered}
$$

где $\Delta \mathrm{V}(\mathrm{t})$ - остаточная сейсмическая вариация; $\left.\partial \mathrm{g}_{\text {лсв }}(\mathrm{t}) / \partial t\right)$ и $*\left(\mathrm{~g}_{\text {лсв }}(\mathrm{t}+1)-\mathrm{g}_{\text {лсв }}(\mathrm{t})\right)-$ соответственно градиент лунно-солнечных вариаций силы тяжести и его численный аналог.

Меняя величину коэффициента К легко получить оптимальный результат.

Примерно также обстоит с гравиметрическими наблюдениями. Здесь исходные данные и лунно-солнечные вариации в одной размерности. Тем не менее, полученная остаточная неприливная вариация с оптимальным значением К осложнена (рис. $3, a$ ) длиннопериодной аномалией. Природа длиннопериодной помехи легко объяснима. Обратимся к рис. $3, b$, на котором приведены графики наблюденных значений атмосферного давления и дневной температуры. Изменение давления (дискретизация 1 час) хорошо коррелируется с изменением неприливной пульсации (рис. $3, a)$. Увеличение давления ведет к увеличению амплитуды сейсмических колебаний (соответственно силы тяжести) и наоборот.

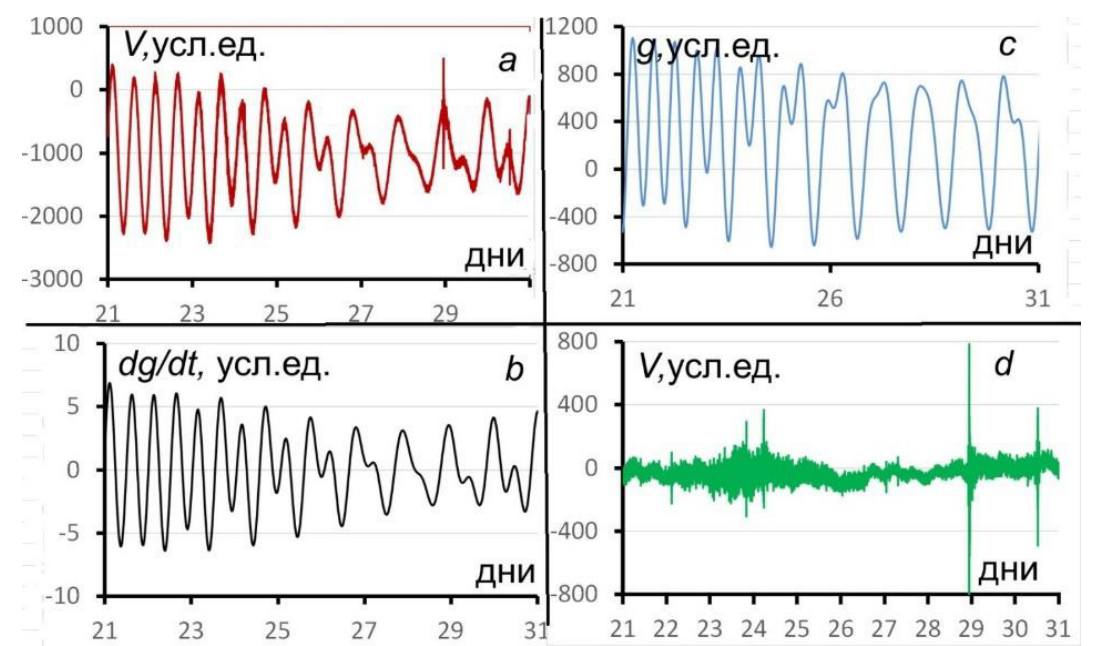

Рис. 2. Сравнение лунно-солнечных вариаций силы тяжести и сейсмической записи на обсерватории FFC: $a-$ сейсмическая запись; $b$ - лунно-солнечные вариации силы тяжести $c$ - градиент лунно-солнечных вариаций силы тяжести; $d$ - пульсация силы тяжести.

[Fig. 2. Comparison of lunar-solar variations of gravity and seismic recording at the FFC Observatory: $a$ - seismic recording; $b$ - lunarsolar variations of gravity; $c$ - gradient of lunar-solar variations of gravity; $d$ - pulsation of gravity.]

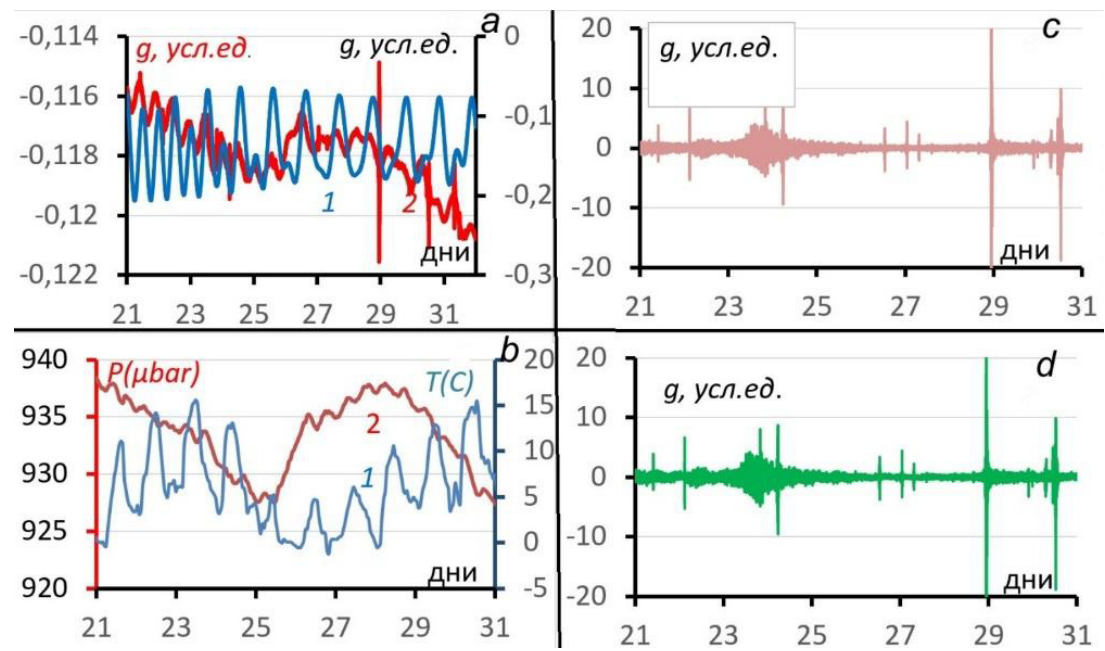

Рис. 3. Сравнение стандартной обработки и методом осреднения (обсерватория DFO): $a$-исходные наблюдения (кривая 1) и данные после учета лунно-солнечных вариаций (кривая 2), $b$ - изменение температуры воздуха (кривая 1) и атмосферного давления (кривая 2), $c$ - остаточная аномалия (пульсация), полученная методом осреднения по данным на рис. $1, a$ (кривая 1); $d$ - остаточная аномалия (пульсация), полученная методом осреднения по данным на рис. $1, a$ (кривая 2).

[Fig. 3. Comparison of standard processing and averaging method (BFO Observatory) $a$-initial observations (curve 1) and data after accounting for lunar-solar variations (curve 2), $b$ - changes in air temperature (curve 1) and atmospheric pressure (curve 2), $c$ - residual anomaly (ripple) obtained by averaging data in figure 1, $a$ (curve 1); $d$-residual anomaly (ripple) obtained by averaging data in figure $1, a$ (curve 2).] 


\section{Результаты и обсуждение}

С влиянием температуры на сейсмические колебания и гравиметрические измерения дело обстоит несколько иначе [7]. Хотя, если взять среднесуточные изменения температуры воздуха, то ее ход находится на данном отрезке времени в противофазе с давлением. В целом же это правило противофазности между среднесуточным ходом температуры и давлением чаще всего соблюдается. Среднесуточный ход температуры определяется многокилометровой толщей атмосферы [7] Дневная температура изменяется в широком диапазоне, но это не влияет на измеренные значения. Дело в том, что температура измеряется на поверхности Земли и отражает состояние только приземного слоя воздуха. Чтобы убрать влияние давления атмосферы и температуры, воспользуемся методом осреднения, так как период изменения метеоусловий в несколько раз превышает периодичность пульсаций [7]

$$
\delta g(\mathrm{t})=g \text { изм }(\mathrm{t})-\sum_{-n}^{n} g \text { изм }(\mathrm{t})(3),
$$

где $\delta g(\mathrm{t})$-исправленная остаточная вариация силы тяжести за давление и температуру; $\sum_{-n}^{n} \Delta g$ изм(t) среднее значение вариации на интервале осреднения ($\mathrm{n}, \mathrm{n})$. Интервал осреднения составляет несколько минут (5-10). А на рис. 3, $d$ представлена такая же остаточная вариация силы тяжести, как и н рис. $3, c$, вычисленная с помощью метода непосредственно по исходным данным, исключая все промежуточные операции, что намного облегчает обработку [8].

Представленные сейсмические пульсации (рис. 1) подтверждаются гравиметрическими пульсациями (рис. 4) на обсерваториях ВFО (Шварцвальд, Германия) и Арти (Екатеринбург, Россия). К сожалению, гравиметрические измерения на других обсерваториях отсутствуют. Можно дополнительно привлечь данные обсерватории с мыса Шульц в Приморском крае [9], которая расположена на границе Тихого океана с Азией (рис. 5). В прибрежной части пульсации возникают не только за счет метеорных потоков. Пульсации за счет метеорных потоков (рис. $5, a$ ) полностью совпадают с сейсмическими пульсациями на рис. 1. Дополнительно на (рис. $5, a$ ) в начале последней декады декабря проявляется пульсация, вызванная метеоусловиями. 21-22 декабря во Владивостоке шел сильный снег, порывы ветра превышали 20 м/с, была отрицательная температура, которая через день сменилась на положительную до+ 5 градусов Метеорных потоков в это время не было. Кстати, на рис. 5, bприведены данные акселерометра, которые полностью повторяют гравиметрическую запись (рис. 5, $a$ ). Акселерометр является составной частью приливного гравиметра, используемого на мысе Шульца. Можно утверждать, что использование акселерометра целесообразно использовать в системе гравиметр-велосиметр.

Пульсации сейсмического поля, создаваемые атмосферными штормами, ураганами и т.д. могут возникать на континентах [4], но они по времени непродолжительны. Другое дело появление пульсаций в приб-
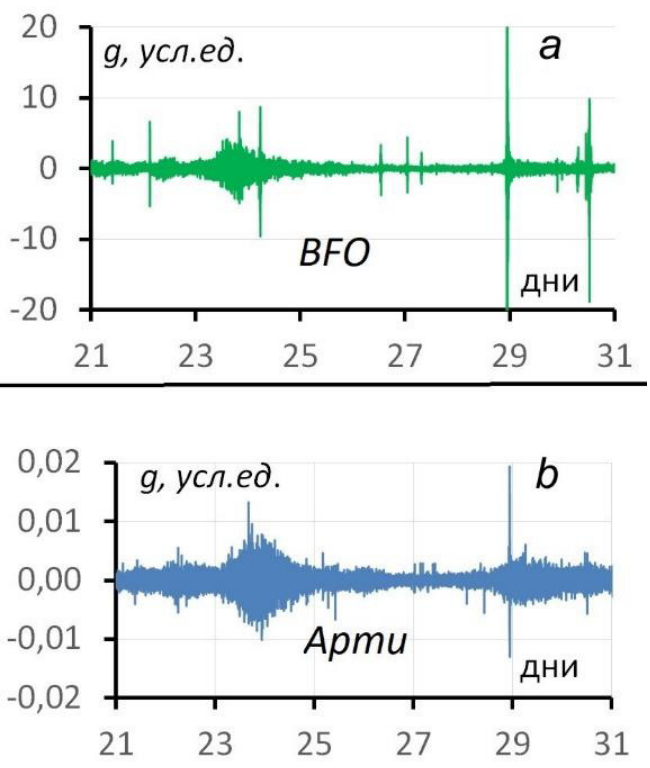

Рис. 4. Сравнение пульсаций силы тяжести в $\mathrm{BFO}(a)$ и Арти (b) 2019 г.

[Fig. 4. Comparison of gravity ripples in $\mathrm{BFO}(a)$ and Arti $(b)$ 2019.]
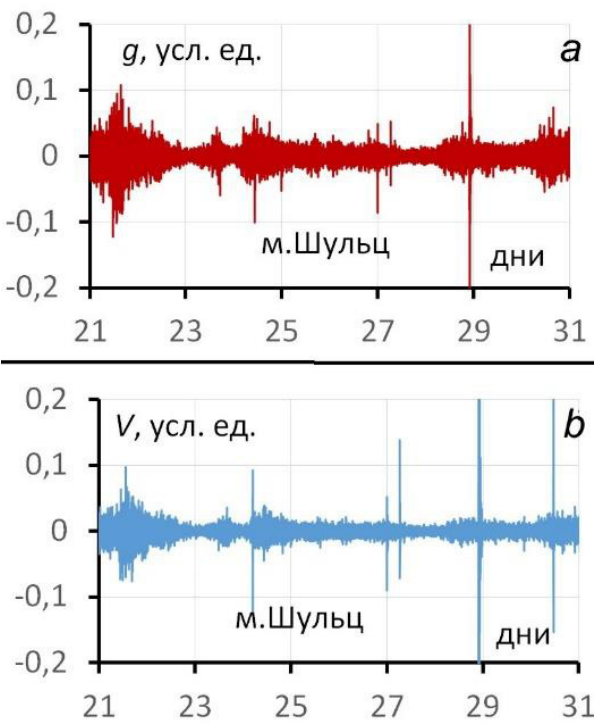

Рис. 5. Сравнение пульсаций силы тяжести $(a)$ и сейсмического поля $(b)$ во Владивостоке.

[Fig. 5. Comparison of gravity ripples $(a)$ and seismic field $(b)$ in Vladivostok.]

режных зонах и океанах. Здесь сила природных стихий в разы больше, чем на суше.

Приведем пример пульсаций в открытом океане (рис. 6). Сейсмические записи отличаются друг от друга. Исходные данные приводятся с дискретностью в 1 с. В Тасмании (рис. 6, a) наблюдается очень выразительная пульсация, которая связана с сильным ветром со снегом на фоне положительной температуры +18 градусов. Амплитуда сейсмической пульсации в несколько раз превышает амплитуды на континентах (рис. 1). В подобных случаях выделить пульсацию, 


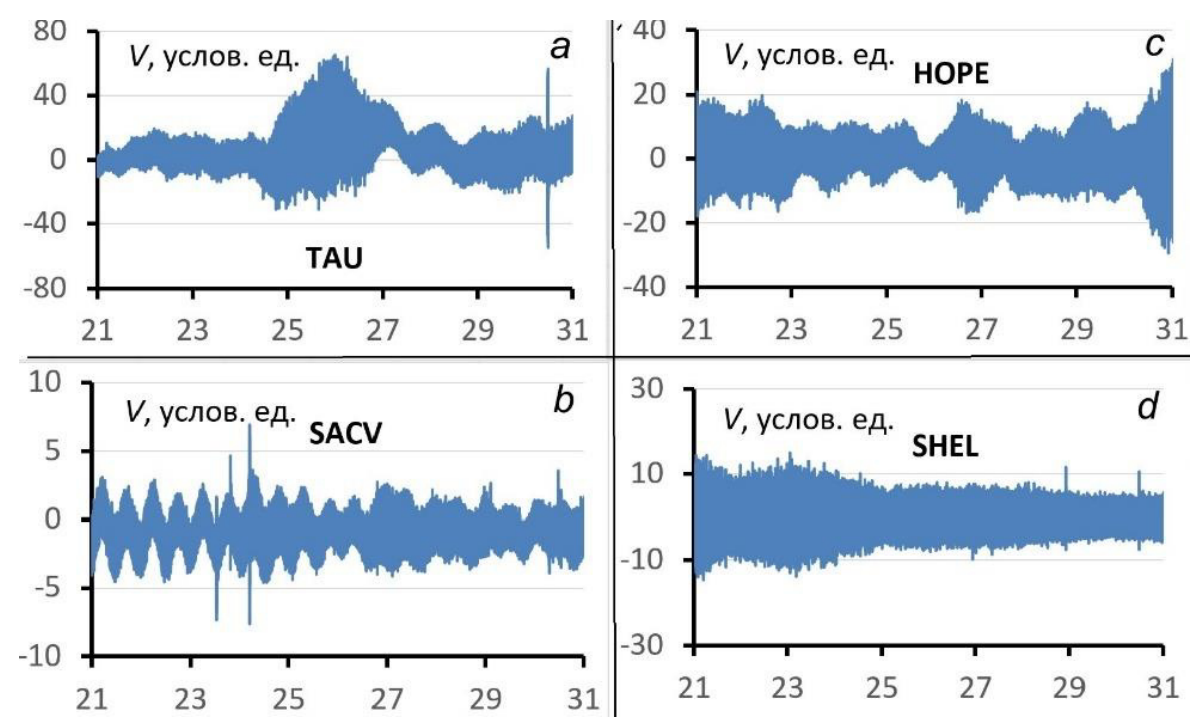

Рис. 6. Характер пульсаций сейсмического поля в океанских акваториях 21 - 31 марта 2019 г.: $a$ - Тасмания (TAU); $b$ - острова Кабо - Верде (SACV); $c$ - острова Южная Джорджия (HOPE); $d$ - остров Святой Елены (SHEL).

[Fig. 6. The Nature of seismic field pulsations in ocean waters on March 21-31, 2019: a - Tasmania (TAU); $b$ - Cape Verde Islands (SACV); $c$ - South Georgia Islands (HOPE); $d$ - Saint Helena (SHEL).]

связанную с метеорным потоком, не представляется возможным.

На островах Кабо-Верде (SACV) в течение всей декады идут равномерные колебания (рис. 6, b) Погода дождливая всю декаду. Наоборот, на островах Юж. Джорджии всю декаду солнечная погода, но очень сильный ветер (рис.6, c) Острова расположены в Атлантическом океане недалеко от Южной Аргентины. В начале и конце декады увеличение амплитуды колебаний объясняются падением давления и усилением ветра. На острове Св. Елены неприливные вариации также соответствуют этому правилу. Вначале декады ливни, сильные ветры, которые концу недели прекратились. Таким образом, пульсации внутри континента и в прибрежной зоне имеют разную природу возникновения (рис. $6 \mathrm{~d})$.

Таким образом, можем использовать стационарные сейсмические и гравиметрические измерения для оценки плотности метеорных потоков.

\section{Выводы}

В результате можно утверждать, что источником пульсаций гравиметрического и сейсмического полей служат метеорные потоки и метеорологические источники (тайфуны, ураганы и т.д.). Первые источники имеют глобальное распространение, а вторые - локальное. Вполне очевидно, что пульсации можно использовать их для глубинного изучения Земли наравне с теллуриками. Можно также использовать для изучения метеорных потоков. В прикладном плане изучение пульсаций внесет определенные коррективы в методику высокоточных измерений силы тяжести.

Благодарности: Автор благодарит за предоставленные сейсмические и гравиметрические материалы
М. Г. Валитова (ТИО ДВО РАН) и Бебнева А. С. (ИГ УрО РАH).

Конфликт интересов: Авторы декларируют отсутствие явных и потенциальных конфликтов интересов, связанных с публикацией настоящей статьи.

\section{ЛИТЕРАТУРА}

1. Антонов Ю. В., Антонова И. Ю. Сравнение приливных вариаций силы тяжести и вертикальной составляющей сейсмографа // Геофизика. 2013. №2. С. 27-31.

2. Абрамов Д. В., Бебнев А. С, Бычков С. Г., Горожанцев С. В., Дробышев М. Н., Овчаренко А. В., Храпенко О. А. Возможная природа пульсаций гравитационного поля // Bonpocbl теории и практики геологической интерпретации гравитаичионных, магнитных и электрических полей. Пермь: Пермский университет, 2019. С. $8-11$.

3. Антонов Ю. В. Пульсации неприливных вариаций силы тяжести // Изв. ВУЗов. Геология и разведка. 2014. № 5. С. 54-57.

4. Антонов Ю. В., Сизаск И. А. Синхронные пульсации в неприливных вариациях гравитационного и сейсмического полей // Геология и разведка. Изв. ВУЗ. 2015. №5. С. 46-52.

5. Монахов Ф. И. Низкочастотный сейсмический шум Земли. М., Наука, 1997.96 с.

6. Project IDA [Электронный ресурc]. URL:

https://sur.ly/i/ida.ucsd.edu/ (дата обращения: 28.10.2018)

7. Антонов Ю. В. Влияние атмосферного фронта на показания гравиметров и сейсмометров // Геология и разведка. 2017. №4. C. 66-71.

8. Антонов Ю. В. Разделение неприливных вариаций силы тяжести на основе спектрального анализа и метода осреднения // Вестник Воронежского государственного университета. Серия: Геология. 2016. № 2. С. 100-106.

9. Прошкина 3. Н., Валитов М. Г., Кулинич Р. Г., Колпащикова Т. Н. Изучение приливных вариаций силы тяжести в зоне перехода от континента к Японскому морю // Вестник КРАУНЦ. Науки о Земле. 2015. №3, Вып.27. С. 71-79.» 
Received: 29.05 .2020

Accepted: 01.06.2020

Published online: 30.06 .2020

\title{
Synchronicity of seismic-induced gravity pulsations
}

\author{
Yu. V. Antonov ${ }^{凶}$, I. Yu. Antonova \\ Voronezh State University \\ 1 Universitetskaya pl., Voronezh 394018, Russian Federation
}

\begin{abstract}
Introduction: Gravity pulsations were first detected when processing stationary observations at the Geodynamic Polygon of the Russian Academy of Sciences in Bishkek (2014). It appeared that the same pulsations were characteristic of seismic vibrations, which synchronously coincided with gravimetric pulsations.

Methodology: Seismic and gravimetric observations are complicated by the influence of the moon and the sun. When processing the data, the main task is to eliminate this effect. Lunar-solar influence can be eliminated by theoretical calculation of lunar-solar variations of gravity and their temporal gradient. Moreover, seismic and gravimetric measurements are influenced by atmospheric pressure and air temperature. Meteorological disturbances are eliminated using the method of averaging.

Results and discussion: The analysis of seismic-induced gravity pulsations on different continents showed that the pulsations are completely synchronous with each other. Such synchronicity is characteristic mostly of the intracontinental stations. Thus, based on the study of seismic-induced gravity pulsations, it can be argued that there are two types of pulsation sources. The first type of pulsation is associated with impacts of meteor showers on the Earth's atmosphere, which has a planetary nature. In the coastal regions and in the ocean, there are additional pulsations caused by atmospheric processes (typhoons, cyclones, etc.) Conclusions: The obtained results can be used further to study the internal structure of the Earth, to determine the power of meteor showers, and increase the accuracy of gravimetric measurements.

Keywords: lunar-solar variations of gravity, non-tidal variations of gravity, mass coronal ejections, meteor showers, pulsations, seismic noise.

For citation: Antonov Yu. V., Antonova I. Yu. Synchronicity of seismic-induced gravity pulsations. Vestnik Voronezhskogo gosudarstvennogo universiteta. Seriya: Geologiya = Proceedings of Voronezh State University. Series: Geology. 2020. No. 2. pp. 76-82. DOI: https://doi.org/10.17308/geology.2020.2/2861

Acknowledgments: The author thanks for the provided seismic and gravimetric materials M.G. Valitova (TIO FEB RAS) and A. Bebneva (IG UB RAS).

Conflict of interests: The authors declare the absence of obvious and potential conflicts of interest related to the publication of this article.
\end{abstract}

\section{REFERENCES}

1. Antonov Yu.V., Antonova I.Yu. Sravnenie prilivnykh variatsiy sily tyazhesti i vertikal'noy sostavlyayushchey seysmografa [Compare tidal variations of gravity and the vertical component seismograph]. Geofizika =Geophysics, 2013, no. 2, pp. 27-31. (In Russ.)

2. Abramov D. V., Bebnev A. S., Bychkov S. G., Gorozhantsev S. V., Drobyschev M. N., Ovcharenko A. V., Khrapenko O.A. Vozmozhnaya priroda pul'satsiyi gravitazionnogo polya [Possi ble nature of gravitational field pulsations ] // Voprosy teorii $i$ praktiki geologicheskoy interpretatsii gravitatsionnykh, magnitnykh I elektricheskikh poley [Questions of the theory and practice of geological interpretation of gravitational, magnetic and electric fields]. Perm. Permskiy univtrsitet. 2019, pp. 8 - 11. (In Russ.) 3. Antonov Yu. V. Pul'satsii neprilivnykh variatsiysily tyazhesti [Ripple tidal gravity variations]. Izvetia vuzov. Geologiya $i$ razvedka $=$ Proc. of the Universities. Geology and exploration. 2014, no. 5, pp. 54-57.2. (In Russ.)

\footnotetext{
\} \text { Yuriy V. Antonov, e-mail: yuriyantonov@yandex.ru }
} 
4. Antonov Yu. V, Sizask I. A. Sinkhronnye pul'satsii v neprilivnykh variatsiyakh gravitatsionnogo i seysmicheskogo poley.[Synchronous ripples innon-tidal variations of gravitational and seismic fields]. Izvetia vuzov. Geologiya i razvedka $=$ Proc. of the Universities. Geology and exploration. 2015, no. 5, pp. 46-52. (In Russ.)

5. Monakhov F.I. Nizkochastotniy seycmicyeskiy schum Zemli [Theory of fluctuations in the earth's atmosphere]. Leningrad: Gidrometeoizdat publ., 1969. 195 p. (In Russ.)

6. Project IDA. Available at: https://sur.ly/i/ida.ucsd.edu/ (accessed 28.10.2018)

7. Antonov Yu. V. Vliyanie atmosfernogo fronta na pokazaniya gravimetrov b seymometrov [Influence of the atmospheric front on the readings of gravimeters and seismometers]. Izvetia vuzov. Geologiya i razvedka = Proc. of the Universities. Geology and exploration. 2017, no. 4, pp. 66-71. (In Russ.)

8. Antonov $\mathrm{Yu}$. V. Razdelenie neprilivnykh variatsiy sily tyazhesti na osnove spektral'nogo analiza i metoda osredneniya [Separation of non-tidal variations of your strength based on spectral analysis and averaging method.]. Vestnik Voronezhskogo gosudarstvennogo universiteta. Seriya: Geologiya = Proceedings of Voronezh State University. Series: Geology, 2016, no. 2, pp. 100-106. (In Russ.)

9. Proshkin Z. N., Valitov M. G., R. G. Kulinich, Kolpashchikov T. N. Izuchenie prilivnykh variatsiy sily tyazhesti $\mathrm{v}$ zone perekhoda ot kontinenta $\mathrm{k}$ Japonskomu moryu [The study tidal variations of gravity in the transition zone from continent to the sea of Japan]. Vestnik KRAUNZ. Nauki o zemle, 2015, no. 3, vol. 27, pp. 71-79. (In Russ.)
Антонов Юрий Васильевич - д. тех. н., профессор, Воронежский государственный университет, Воронеж, Российская Федерация; E-mail: yuriyantonov@yandex.ru; ORCID http://orcid.org/0000-0002-3323-9697

Антонова Ирина Юрьевна - преподаватель, Воронежский государственный университет, Воронеж, Российская Федерация; E-mail: mavka_r@mail.ru ORCID http://orcid.org/0000-0001-5851-3122

Авторы прочитали и одобрили окончательный вариант рукописи.
Yuriy V. Antonov - Dr. habil. in Techn., Professor, Voronezh State University, Voronezh, Russian Federation;

E-mail: yuriyantonov@yandex.ru;

ORCID http://orcid.org/0000-0002-3323-9697

Irina Yu. Antonova - Lecturer, Voronezh State University, Voronezh, Russian Federation;

E-mail: mavka_r@mail.ru

ORCID http://orcid.org/0000-0001-5851-3122

All authors have read and approved the final manuscript. 